Aksaray University
Journal of Science and Engineering
e-ISSN: 2587-1277
http://dergipark.gov.tr/asujse
http://asujse.aksaray.edu.tr

Research Article

\title{
Speed Control of DC Motor under Reverse Torque Disturbance with Ant Colony Optimized PID Controller
}

\author{
Ömer KASIM* \\ Department of Electrical Electronics Engineering, Faculty of Simav Technology, Kutahya Dumlupinar University, \\ 43500, Turkey \\ -Received Date: Mar 08, 2021 \\ -Revised Date: Mar 25, 2021 \\ -Accepted Date: Apr 03, 2021 \\ -Published Online: Apr 21, 2021
}

\begin{abstract}
Direct Current (DC) motors are widely used in industrial systems due to their high torque. In ensuring the stability and productivity of a system, it is important that the DC motor within the automation system reaches the reference speed value quickly and its speed remains constant under load. In this study, it is aimed to keep the speed value of DC motor constant under load by optimizing the gain parameters of the Proportional, Integral and Derivative (PID) controller, which is widely used in industrial applications. In the optimization of these parameters, the Ziegler Nichols method (ZNM) and the Ant Colony Optimization method (ACO) were examined comparatively in the simulation environment. PID parameters were determined by open loop responses under the running system with the ZNM. On the other hand, the most optimum solution was obtained among many parameters with the ACO method. Speed control of DC motor was performed with PID controller parameters which are determined according to the best ACO response. Simulation results are presented in comparison with the parameters of settling time, peak time, rising time and response of the system under load. As a result, PID controller run with $\mathrm{K}_{\mathrm{p}}, \mathrm{K}_{\mathrm{i}}$, and $\mathrm{K}_{\mathrm{d}}$ parameters obtained by ACO algorithm generally gave better results than $\mathrm{ZNM}$.
\end{abstract}

Keywords DC Motor Speed Control, PID Controller, Ziegler Nichols method, Ant Colony Optimization method

*Corresponding Author: Ömer KASIM, omer.kasim@dpu.edu.tr $@ \underline{0000-0003-4021-5412}$ 


\section{INTRODUCTION}

In a control system design, it is advantageous to simulate the system by modeling instead of damaging the physical system or reconstructing it with changing parameters [1]. It is possible to improve the most optimum operating range of the Direct Current (DC) motor in the simulation environment. DC motors, which are the subject of this study and widely used in the industrial field, are easily linearly controllable [2]. PID controller is used in system control in approximately $90 \%$ of industrial applications [3]. In linear control processes, transient and steady state characteristics are improved by generally applying PID control strategy to DC motors [4]. This improvement is realized by determining the values of 3 parameters named as proportional gain coefficient (Kp), integral gain coefficient (Ki) and derivative gain coefficient $(\mathrm{Kd})$. In the speed control of the DC motor, it depends on the optimum selection of $\mathrm{Kp}, \mathrm{Ki}$ and $\mathrm{Kd}$ of the controller. In practice, these three parameters are adjusted manually by matching with the automation system and set them for all operating situations [5]. However, it is possible to find more optimum solutions if the analysis of the load cases that the system will be exposed to is made with optimization algorithms in the simulation environment. As a result, the advantages of commonly used PID and intelligent algorithm can be integrated to reduce parameter setting cost, improve tuning efficiency and system stability [6].

Various studies have been presented in the literature for the optimum selection of the gain parameters of the PID controller. The Ziegler-Nichols method (ZNM), which is the most classical form of these, is based on the open loop operation of the system [7]. Hammoodi et al. provided the speed control of DC motor with a PID controller. The authors designed the simulation environment by considering the electrical and mechanical parts of the dc motor separately. With this design, it is stated that when the reverse torque situation that will occur under load is simulated, the PID controller can keep the speed of the motor constant against the load [8]. Alqahtani et al. carried out speed control of DC motor without load in simulation environment with PI and PID controller. The authors explained that they got similar results from PI and PID controller in the simulation environment. However, they did not mention the control process of the DC motor under load [9]. Khan et al. simulated a DC motor under different torque loads. The authors designed the PID controller using the ZNM. They experimentally demonstrated that the PID controller obtained satisfactory results, especially under load [10]. Parnianifard et al. simulated 5 different DC motors with a PID controller. It was stated by the authors that models tested with multiple cycles using PI, PID and fractionalorder PID under different load conditions gave more durable results [11]. Faisal measured the 
speed response of the asynchronous motor in his study. The author analyzed the PID controller gain parameters obtained with the conventional experiment and the gain parameters obtained with the Ant Colony Optimization (ACO) algorithm. As a result of the analysis performed with an uncontrolled induction motor, it was explained that the ACO algorithm provides faster convergence with a minimum fit function. However, no analysis under load was included in the study [12]. Farahani et al. examined the improvement of rise time and settlement time in their work. The authors achieved very successful results by optimizing the fractional-order PID controller in their experimental work. However, the results of the ACO algorithm were not discussed in the study [13]. Dutta et al. obtained better sitting time with the PID controller parameters they optimized with the gray wolf optimization algorithm [14]. However, the torque situation changing with the load was not examined in this study.

Although many techniques are successful in automatically adjusting the PID parameters, the robustness of the speed control of the DC motor depends on the optimum selection of PID controller $\mathrm{Kp}, \mathrm{Ki}$, and $\mathrm{Kd}$ gain parameters. Various algorithms for the best selection are presented in the literature. The most popular of these is the Ziegler-Nichols method. However, it is possible to choose more optimized parameters according to this method. For this purpose, optimization methods are preferred in parameter estimation. The ACO is capable of populationbased optimization has robustness and ease of use.

This article presents a comprehensive experiments of PID controller optimization with the ACO method and the ZNM for DC motor speed control. The parameters of the ACO are adjusted to match the optimum $\mathrm{K}_{\mathrm{p}}, \mathrm{K}_{\mathrm{i}}$, and $\mathrm{K}_{\mathrm{d}}$ parameters. In the simulation environment of the DC motor whose mathematical model is known, the PID coefficients of the DC motor in the simulation environment were determined by the ACO algorithm. Transient and steady state states were compared with the results of Ziegler Nicholes in the simulation study performed with the PID controller created with $\mathrm{K}_{\mathrm{p}}, \mathrm{K}_{\mathrm{i}}$, and $\mathrm{K}_{\mathrm{d}}$ values obtained from the ACO algorithm. In the simulation environment, it has been observed that the PID controller with the coefficients obtained with the ACO obtains a faster response in the speed control of the DC motor under load.

\section{MATERIALS AND METHODS}

Obtaining $K_{p}, K_{i}$, and $K_{d}$ parameters of the PID controller, which is widely used in the speed control of DC motor, is of vital importance for the controlled plant. These parameters were optimized with ACO algorithm and speed control of DC motor was realized in this study. The DC motor is driven by the PID controller according to the error value $\mathrm{e}(\mathrm{t})$ obtained by the difference between the step input $\mathrm{r}(\mathrm{t})$ and $\mathrm{c}(\mathrm{t})$ 
coming from the system output. In the PID controller, the proportional integral and derivative gain parameters are connected in parallel. The $\mathrm{u}(\mathrm{t})$ signal is obtained by adding three different values. The control signal is applied to the electrical part of the motor, which is the armature side. The mechanical part moves with the changes in the electrical part. This movement happens with torque. In simulation experiments, an inverse torque $\mathrm{d}(\mathrm{t})$ that is almost inverse to the torque value of the motor is applied. The flow diagram of the simulation environment prepared for speed control is presented in Fig. 1. The optimum solution was obtained by running multiple simulations to optimize the system $K_{p}, K_{i}$, and $K_{d}$ parameters with ACO.

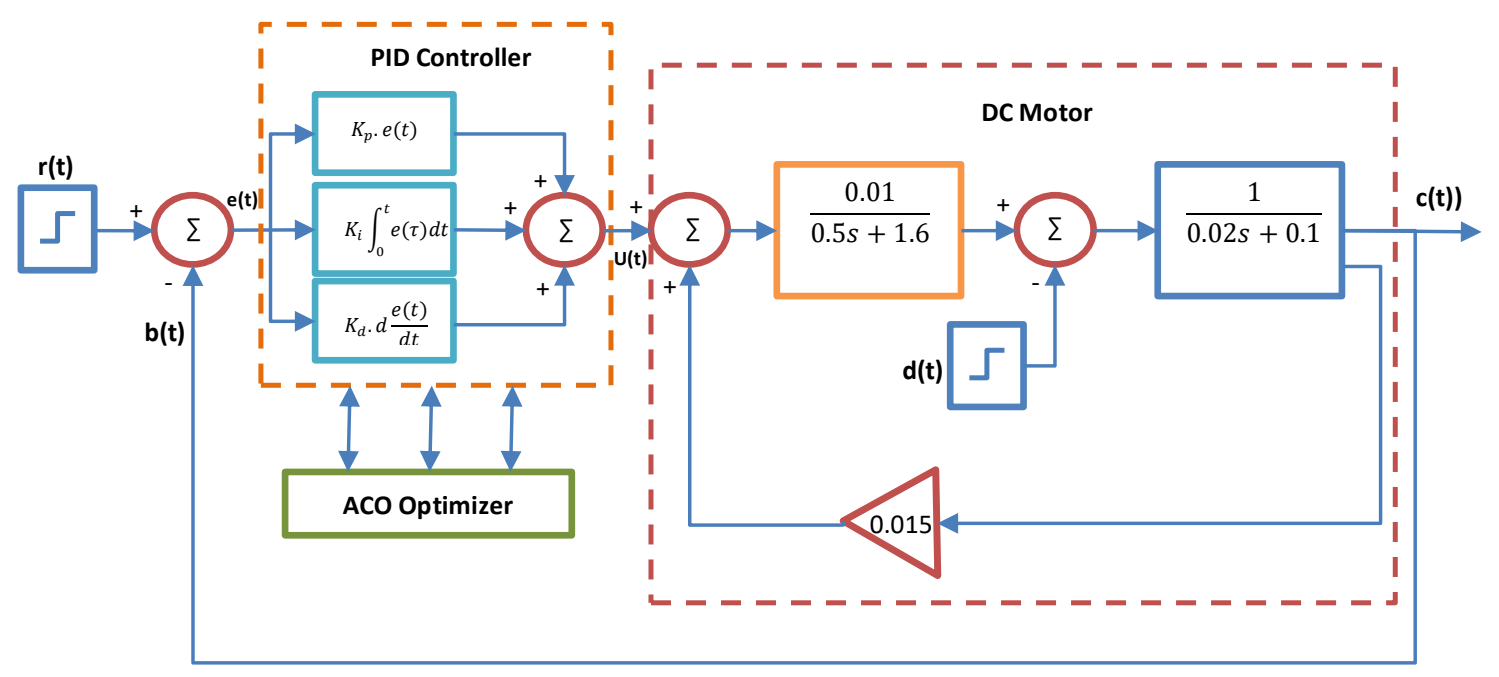

Figure 1. Flow Chart of the Proposed Method

\subsection{Mathematical Modeling of DC Motor}

A DC motor has been created with two subsystems. The first subsystem is the electrical part and consists of armature inductance, armature resistance, and the magnetic flux of the stator. The mechanical part is the second subsystem consisting of the inertia of the motor and the load. Changes in motor speed are caused by amplifier current, load and electromagnetic moment caused by motor friction [15]. Fig. 2 shows a simplified electrical circuit of a DC motor and a mechanical model of a rotor.

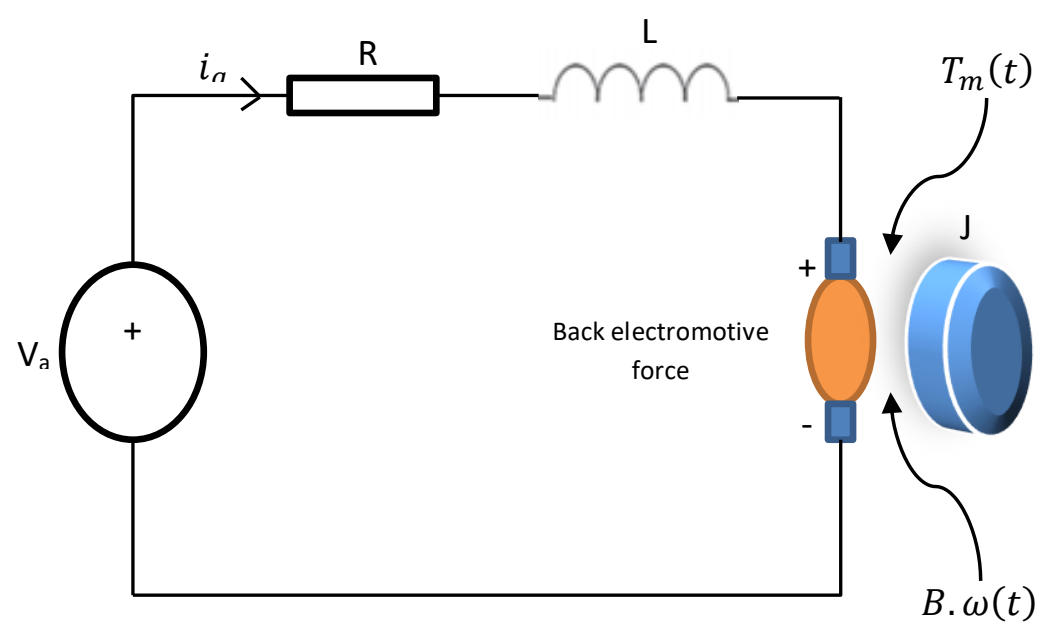

Figure 2. DC Motor Diagram 
The dynamic behavior of a DC motor based on a mathematical model is expressed by differential equations in a simulation environment. The mechanical part is modeled by Eq. 1, while the electrical part is modeled by Eq. 2. Transformation expressions between the two systems are expressed by Eq. 3 and Eq. 4.

$J \cdot \frac{d \omega(t)}{d t}+B . \omega(t)=T_{m}(t)$

$L \cdot \frac{d i_{a}(t)}{d t}+R \cdot i_{a}(t)=v_{a}(t)-v_{b}(t)$

$v_{b}=K_{e} . \omega(t)$

$T_{m}(t)=K_{t} \cdot i_{a}(t)$

The parameters of the DC motor used in this study, whose mathematical model is obtained by equations, are described in Table 1 [11].

The transfer function of the system is expressed in Eq. 5. It is used to express the behavior of the noload DC motor with the transfer function obtained by the ratio of angular velocity to input voltage.

$\frac{\omega(s)}{V_{a} T(s)}=\frac{1}{s^{2}+8.2 s+16.015}=\frac{0.01}{0.01 \times 0.015+(0.02 s+0.1)(0.5 s+1.6)}$

Table 1. Physical parameters of the DC motor model

\begin{tabular}{clcc}
\hline Parameters & Explanations & Unit & Value \\
\hline$V_{a}$ & Input Voltage & Volt & $\mathrm{R}(\mathrm{s})$ \\
$\omega$ & Angular velocity of the shaft & $\mathrm{Rad} / \mathrm{s}$ & $\mathrm{C}(\mathrm{s})$ \\
$\mathrm{R}$ & Armature resistance & $\mathrm{Ohm}(\Omega)$ & 1.6 \\
$\mathrm{~L}$ & Armature Inductance & $\mathrm{Henry}$ & 0.5 \\
$\mathrm{~J}$ & Moment of inertia & $\mathrm{Kg} / \mathrm{m}^{2}$ & 0.02 \\
$K_{t}$ & Torque constant of the motor & $\mathrm{N}-\mathrm{m} / \mathrm{Amp}$ & 0.015 \\
$K_{e}$ & Opposite EMF constant & $\mathrm{V} / \mathrm{rad} / \mathrm{s}$ & 0.01 \\
$\mathrm{~B}$ & Viscous Damping & $\mathrm{Nm} / \mathrm{rmp}$ & 0.1 \\
\hline
\end{tabular}

\subsection{PID Controller Optimization with ACO Algorithm}

The PID controller, which is widely used in industrial applications, is used in closed loop systems. The principle of driving the system according to the error signal $(\mathrm{e}(\mathrm{t}))$, which is the difference between the output of the system and the reference input, is used in the controller. Three parameters, $K_{p}, K_{i}$, and $K_{d}$, are used to reduce the error signal to near zero in the controller. In Eq. 6 in which these parameters are expressed, the control signal $\mathrm{u}(\mathrm{t})$ is obtained [16].

$u(t)=K_{p} \cdot e(t)+K_{i} \int_{0}^{t} e(t) \cdot d t+K_{d} \cdot \frac{d e(t)}{d t}$ 
The effectiveness of the PID controller depends on the gain coefficients $K_{p}, K_{i}$, and $K_{d}$. Choosing these coefficients as optimum affects the performance of the system positively.

One of the algorithms used in the PID controller to optimize the gain coefficients is the ZNM. Firstly, the critical gain of the open loop system is obtained by calculating the $K_{p}, K_{i}$, and $K_{d}$ coefficients of the PID controller with the ZNM. Then, a critical gain value is measured by increasing the Kp at which the system provides continuous oscillation. Finally, the three control parameters of the respective period PID controller are calculated using the transformation table in the ZNM [17]. Another algorithm that enables the gain coefficients used in the PID controller to be optimized is the ACO algorithm. This algorithm was developed based on the behavior of ants living in nature. When ants living in a colony encounter an obstacle to reach their goals, finding the shortest distance contributes to the solution of optimization problems [18]. The shortest path is based on the follow-up of an ant's pheromone secretion by other ants. Increasing the amount of ants passing through the preferred route results in an increase in the amount of pheromone. Thus, the shortest path is obtained. If the road needs to be changed, the probability of new direction selection becomes equal. In this case, if it is not the shortest route, a new route is quickly found by the colony [19].

While creating ACO, first, some assumptions are made and artificial ants are created [20]. These ants work in parallel in the colony. Each ant is placed in different places or at the same point according to the input-output relationship of the system modeled in determining the optimum of $K_{p}, K_{i}$, and $K_{d}$ coefficients. The neighboring point of the ants is determined by the probability formula shown in Eq. 7 at time $\mathrm{t}$.

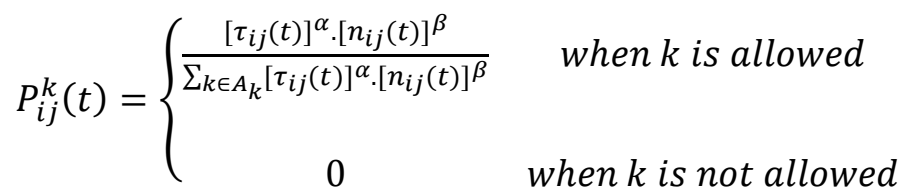

In Eq. 7, where ants move from node $i$ to node $j$, alpha $(\alpha)$ and beta $(\beta)$ are two parameters that determine the relative effect of the trace pheromone $\left(\tau_{\mathrm{ij}}\right)$ and the heuristic information called visibility $\left(\mathrm{n}_{\mathrm{ij}}\right)$.

In each iteration, the initially created ants choose a path between the start and end nodes and use each $\mathrm{Kp}, \mathrm{Ki}, \mathrm{Kd}$ parameters. At the end of each iteration, the pheromone left by each ant and Eq. 8 is used to update the decisions of this pheromone.

$\tau_{i j}(t)=\tau_{i j}(t-1)+0.01 \frac{\alpha}{c_{n n}}$

Upon completion of a round, each ant releases the pheromone in the paths and $\tau_{i j}(t)$ is updated using the local pheromone update rules given in Eq. 8. It can be positive or negative in the update process with Eq. 8. In each iteration, the best $\tau_{i j}^{b}(t)$ and the worst $\tau_{i j}^{w}(t)$ colony pheromones are obtained by Eq. 9 and Eq. 10. 
$\tau_{i j}^{b}(t)=\tau_{i j}^{b}(t)+\frac{\alpha}{c_{b}}$

$\tau_{i j}^{w}(t)=\tau_{i j}^{w}(t)-0.3 \frac{\alpha}{c_{w}}$

With Eq. 9 and Eq. 10, while the pheromone rate increases in the best round of the colony, the rate of pheromone decreases in the worst round. After some iteration, the pheromone is completely deleted. This situation, called evaporation of pheromones, is obtained with Eq. 11 and Eq. 12. The ACO algorithm forgets the past with these equations.

$\tau_{i j}(t)=\tau_{i j}(t)^{\gamma}+d$

$d=\tau_{i j}^{b}(t)+\tau_{i j}^{w}(t)$

Each node in the ACO algorithm represents a solution value of the gain parameters $K_{p}, K_{i}$, and $K_{d}$. Increasing the number of nodes in the algorithm makes the routes used by the ants more distinct. The $\alpha$ and $\beta$ parameters optimized by the ACO algorithm are obtained by many trials. In order to prevent the $\mathrm{ACO}$ algorithm to work in a wide range and not to specify exact parameters, the minimum and maximum values of the algorithm and the search area were not chosen too large at the beginning. Also, when the search field was selected small, successful results were not obtained. Likewise, the wide selection of the search area has also extended the processing time.

\section{RESULT AND DISCUSSION}

In this study, a PID controller, in which optimum gain values are obtained with the ACO, is designed in order that the speed control of the DC motor can follow the reference input under full load. The graphic in Fig. 3 was obtained when DC motor was operated in closed loop without using PID controller. In the tenth second of the simulation, a step input of 100 units was applied, whereas an output of only 6 units was seen at the output of the DC motor.

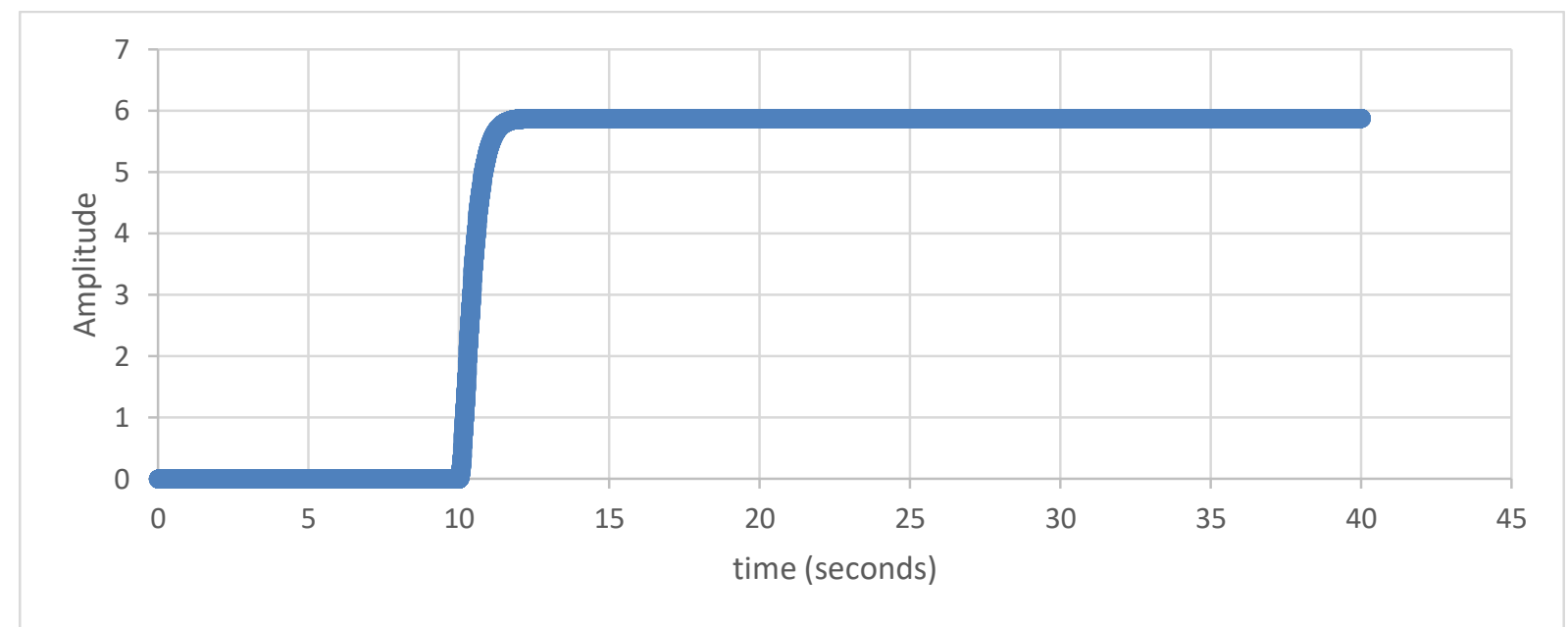

Figure 3. Closed Loop 100-unit step input response graph of DC motor 


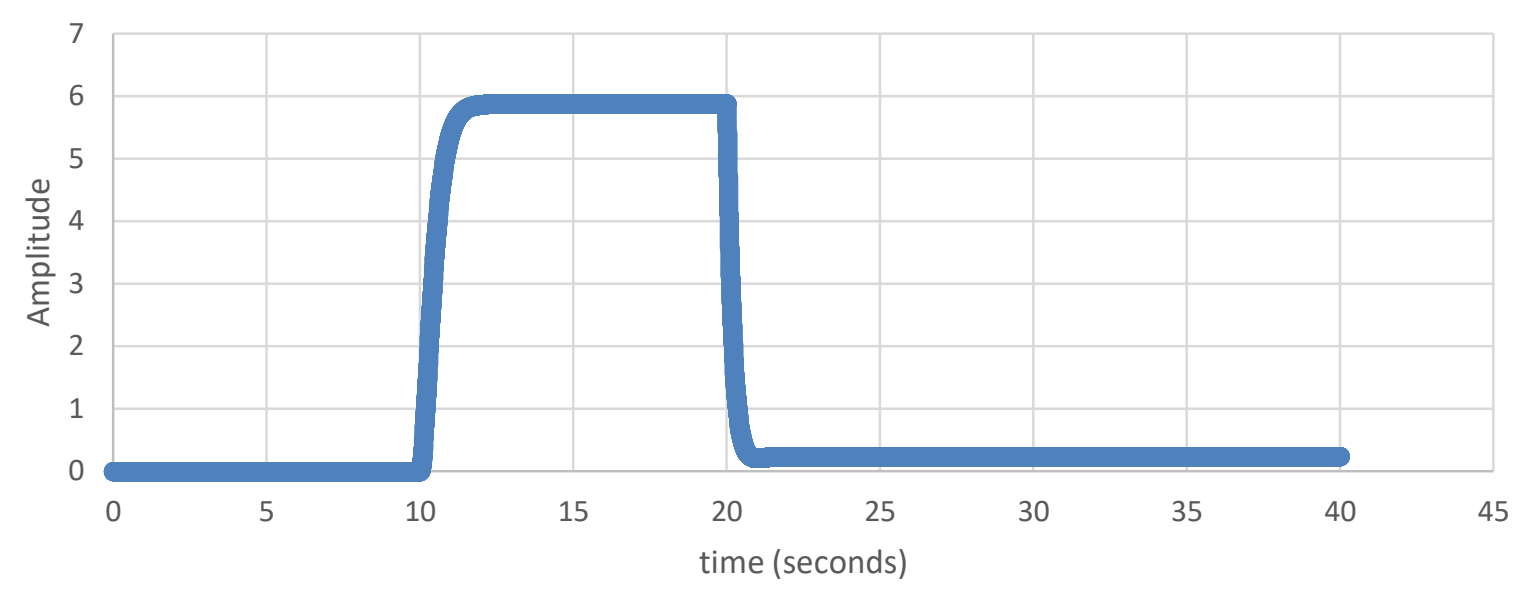

Figure 4. Closed Loop 100-unit step input response graph of DC motor under load

The result in Fig. 4 was obtained only in closed loop with the operation of the engine under full load. Again, when the 100-unit step input was applied in ten seconds, the system showed 6-unit output. The closed loop system under load could not compensate for the error with the distorting torque applied in the twentieth second. Engine speed was achieved almost close to zero.

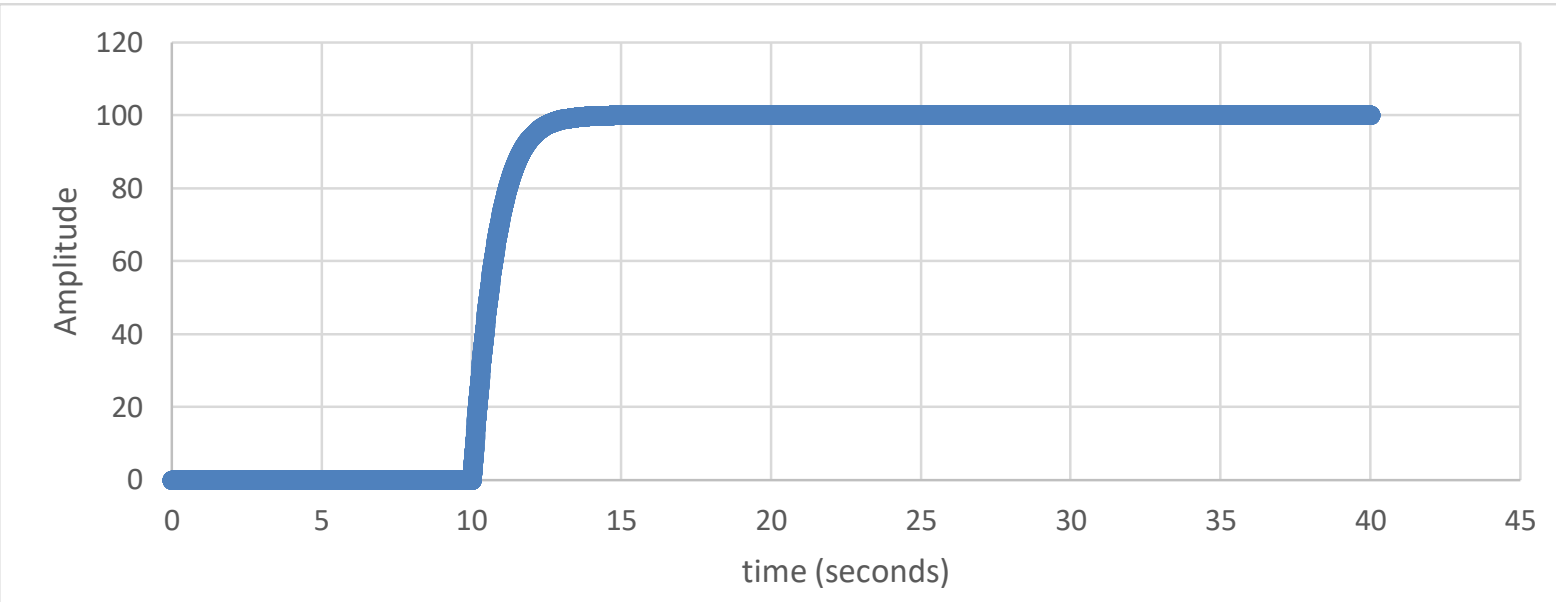

Figure 5. Closed Loop 100 unit step input response graph of DC motor with PID Controller optimized with ZNM

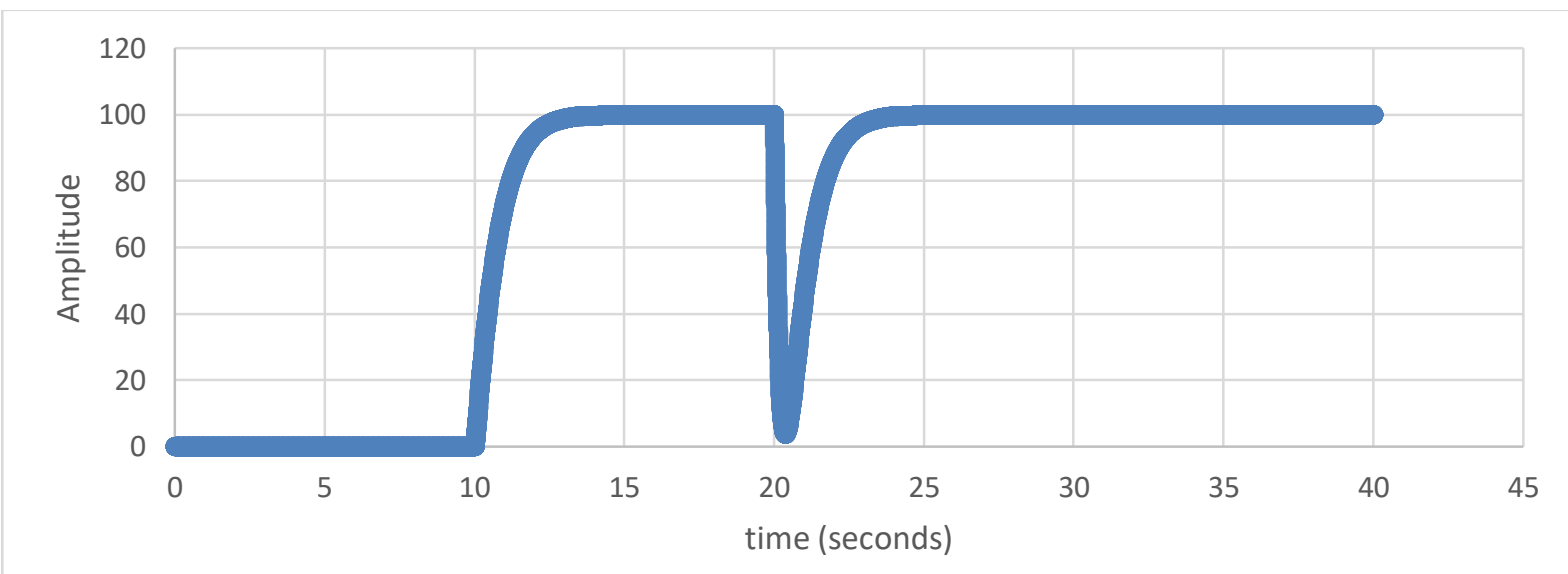

Figure 6. Closed Loop 100-unit step input response graph of DC motor with PID controller optimized with ZNM under load 
With the Ziegler Nicholes method, the parameters of the selected controller type (P, PI, PID) are calculated by using the transfer function of the system to ensure a good balance between system performance and robustness. The $K_{p}, K_{i}$, and $K_{d}$ values calculated by $Z N M$ are $K_{p}=9.6073, T_{i}=0.4497$, $\mathrm{T}_{\mathrm{d}}=0.1124, \mathrm{~K}_{\mathrm{i}}=21.3637 \mathrm{~K}_{\mathrm{d}}=1.0798, \mathrm{~W}_{\mathrm{c}}=6.9855, \mathrm{~T}_{\mathrm{c}}=0.8995$, respectively. It was calculated as $\mathrm{K}_{\mathrm{c}}=16.0122$. When the system tuned with these parameters was driven with a PID controller, it was able to follow a 100-unit step input. As seen in Fig. 5, the step applied in the tenth second is the entrance system. The system was able to compensate the error according to the reference input again by compensating the error with the PID controller against the disturbing effect given in the twentieth second in the simulation. This situation is shown in Fig. 6.

Optimizing PID parameters using the ACO method first starts with the number of ants, the number of selected paths and the population of the PID parameters. In optimization starting with these parameters, the cost function is evaluated. The optimum values of the PID parameters $K_{p}, K_{i}$, and $K_{d}$ are updated at every iteration. Optimization is stopped when the maximum number of iterations is reached or when the objective function criterion is obtained. In this study, the input parameters for the ACO algorithm are used as shown in Table 2 to obtain the optimum PID controller gain parameters.

Table 2. Input parameters of the ACO algorithm

\begin{tabular}{lc}
\hline Input Parameters & Value \\
\hline Number of ants & 100 \\
Number of Iterations & 150 \\
Number of reviews & 2000 \\
Number of Nodes & 1000 \\
Pheromone Amount & 50 \\
Decay Parameter $(\rho)$ & 0.7 \\
PID parameter ranges & {$[0.1-50]$} \\
\hline
\end{tabular}

When the decay parameter, $\rho$, is closer to 1 , the probability of reaching the optimal solution is high, but the convergence rate is slow. On the other hand, for $\rho$ near 0 , it is possible to obtain a solution from the local optimal solution with faster convergence ratio. In this study, the decay parameter 0.7 was chosen to reach the best solution. In order to reach an optimal solution, the number of nodes $\mathrm{M}$ was chosen high and $\mathrm{Q}$, which is the amount of pheromone per iteration, was chosen as the small value. Simulink model is run at each iteration and the speed of the DC motor is simulated with $K_{p}, K_{i}$, and $K_{d}$ values. Each ant replaces the pheromones of its tracks in one round with local pheromone update, and the global pheromone update is performed by finding positive and negative update values according to the best 
and worst ants. Pheromone evaporation is also done to make the ants move in new directions. PID parameters and cost values are best determined by the ant. After the cycle is completed by reaching the maximum number of turns, the lowest cost coefficients are obtained. The lowest cost values show the best parameters. As shown in Fig. 7 and Fig. 8 as a result of simulation with $K_{p}, K_{i}$, and $K_{d}$ values resulting from ACO application, the overrun, rise time and settlement time are significantly improved compared to the ZNM.

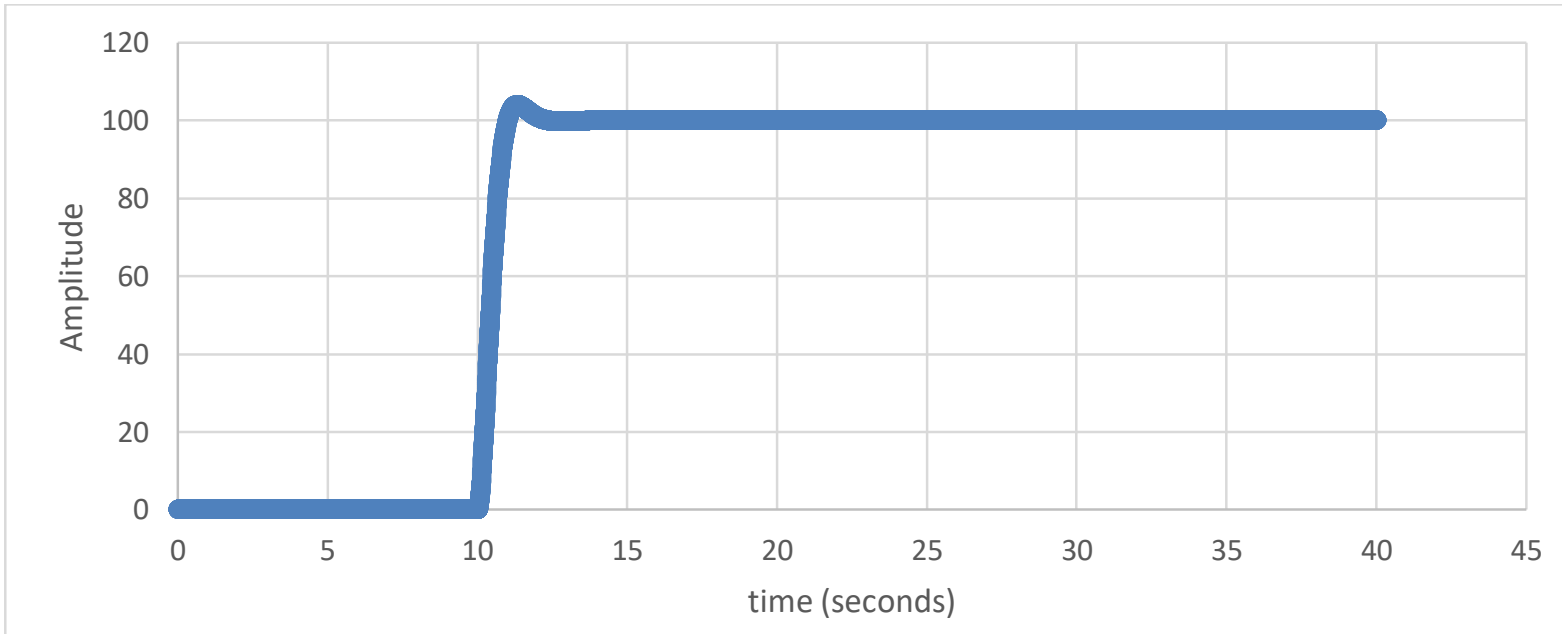

Figure 7. Closed Loop 100-unit step input response graph of DC motor with PID Controller optimized with ACO

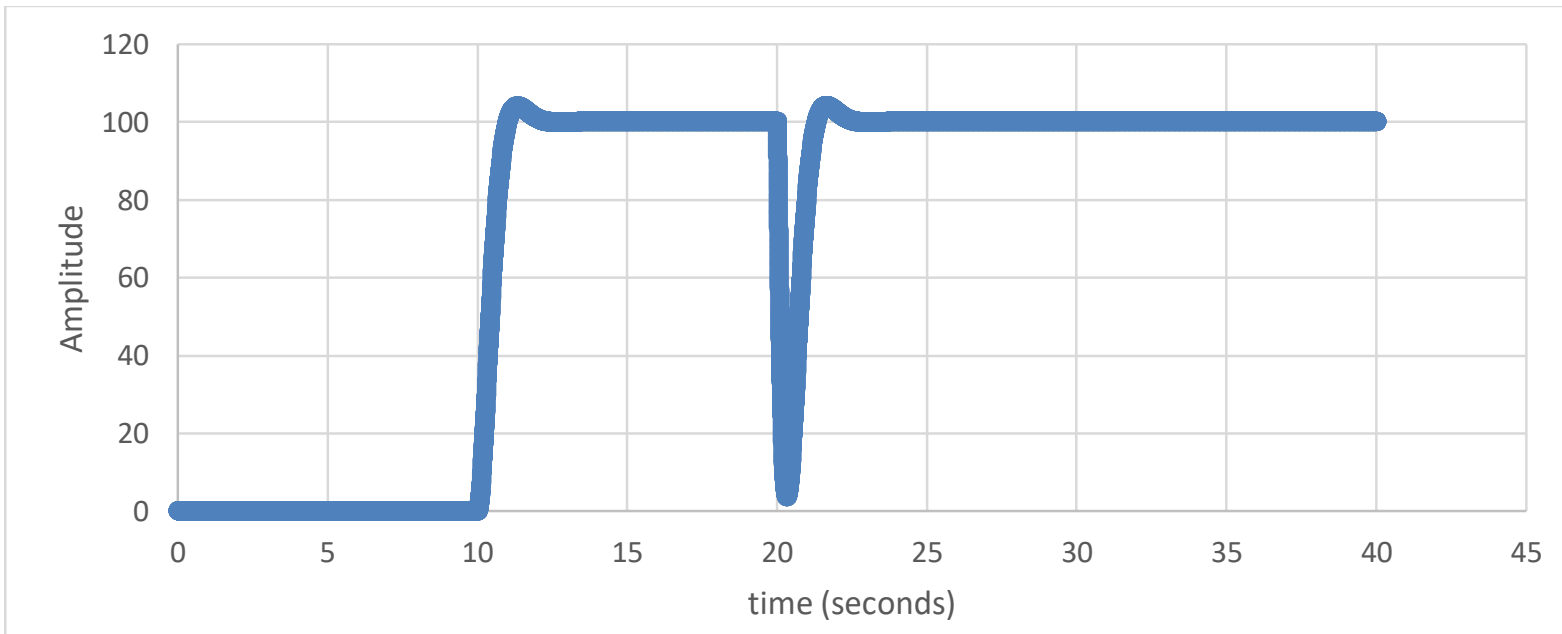

Figure 8. Closed Loop 100-unit step input response graph of DC motor with PID Controller optimized with ACO under load

In the study, $\mathrm{K}_{\mathrm{p}}, \mathrm{K}_{\mathrm{i}}$, and $\mathrm{K}_{\mathrm{d}}$ values calculated by ACO and ZNM. Then, the simulation analysis against unit step input of speed control of DC motor were comparatively performed. The parameters in Table 3 were obtained as a result of the simulation of the closed loop control of the DC motor with PID parameters optimized with ACO and ZNM. In closed loop control, the motor cannot reach the desired speed level. It has been observed that the metrics of the DC motor optimized with ACO is more successful. 
Table 3. Performance metrics of the methods

\begin{tabular}{lccc}
\hline Definition & $\begin{array}{c}\text { Rising } \\
\text { Time }\left(\mathbf{t}_{\mathbf{r}}\right)\end{array}$ & $\begin{array}{c}\text { Peak } \\
\text { Time }\left(\mathbf{t}_{\mathbf{p}}\right)\end{array}$ & $\begin{array}{c}\text { Settling } \\
\text { Time }\left(\mathbf{t}_{\mathbf{s}}\right)\end{array}$ \\
\hline Closed Loop Speed Control of DC Motor & 0.8697 & 2.5693 & 1.5268 \\
$\begin{array}{l}\text { DC motor speed control with PID parameters } \\
\text { optimized with ZNM }\end{array}$ & 0.6440 & 1.3309 & 1.7597 \\
$\begin{array}{l}\text { DC motor speed control with PID parameters } \\
\text { optimized with ACO }\end{array}$ & 1.5616 & 4.5538 & 2.6843 \\
\hline
\end{tabular}

It is stated in the experimental results that when the DC motor is under full load, with closed loop control, the speed decrease to almost zero is corrected by PID controller. However, with the PID parameters obtained with the ACO, a faster response was produced against the disturbing effect by responding faster. Although it was observed that there was no overshoot with the PID parameters optimized with ZNM, it was observed that the dc motor reached the desired speed level with a faster response with ACO for a little exceeding. Parnianifard et al. controlled a dc motor's PID controller with the same parameters in their study [11]. Although the authors achieved faster rising and settling time with PID tuning, it was observed that there was an increase in the amount of overshot.

\section{CONCLUSION}

Considering that the ACO algorithm provides effective and successful results for optimization problems, this article discusses the use of ACO to determine the PID parameters for speed control of a DC motor. The parameters determined by the proposed ACO-based method are compared with the results of the parameter determination process using the ZNM. It was observed that the ACO-based method provides better results in terms of rise time, setting time and overshoot values. A more optimal solution was obtained with the model proposed in the study. In addition, the load is modeled with reverse torque in the study. Even under full load, the proposed method can keep the reference input of the DC motor.

\section{REFERENCES}

[1] S. He, L. Liu, X. Hu, J. Xiao, Research on integrated simulation technology of multi-source heterogeneous model based on FMI standard. 13th IEEE Conference on Industrial Electronics and Applications. (2018) 417-422.

[2] J. Lopez-Gomez, M.A.D. Vargas-Treviño, S. Vergara-Limon, M. Vargas-Treviño, J. GutierrezGutierrez, A.D. Palomino-Merino, O.G. Felix-Beltran, Influence of PWM torque control frequency in DC motors by means of an optimum design method. IEEE Access. 8 (2020) 80691-80706.

[3] N. Saridhar, N. Ramrao, M.K. Singh, PID controller auto tuning using ASBO technique. Journal of Control Engineering and Technology. 4(3) (2014) 192-204.

[4] H. Liang, J. Zou, K. Zuo, M.J. Khan, An improved genetic algorithm optimization fuzzy controller applied to the wellhead back pressure control system. Mechanical Systems and Signal Processing. 142 (2020) 106708. 
[5] J. Mendes, L. Osório, R. Araújo, Self-tuning PID controllers in pursuit of plug and play capacity. Control Engineering Practice. 69 (2017) 73-84.

[6] P.J. Fleming, R.C. Purshouse, Evolutionary algorithms in control systems engineering: A survey. Control engineering practice. 10(11) (2002) 1223-1241.

[7] P. Meshram, R.G. Kanojiya, Tuning of PID controller using Ziegler-Nichols method for speed control of dc motor. IEEE Int. Conf. Adv. Eng., Sci. Manage. (2012) 117-122.

[8] S.J. Hammoodi, K.S. Flayyih, A.R. Hamad, Design and implementation speed control system of DC motor based on PID control and matlab simulink. International Journal of Power Electronics and Drive Systems. 11(1) (2020) 127.

[9] S. Alqahtani, S. Ganesan, M.A. Zohdy, The Comparison between PI and PID Controllers in Engine Speed Control Model. IEEE International Conference on Electro Information Technology. (2020) 629-634.

[10] M.R. Khan, A.A. Khan, U. Ghazali, Speed Control of DC Motor under Varying Load Using PID Controller. International Journal of Engineering. 9(3) (2015) 38-48.

[11] A. Parnianifard, A.S. Azfanizam, Metamodel-based robust simulation-optimization assisted optimal design of multiloop integer and fractional-order PID controller. International Journal of Numerical Modelling: Electronic Networks, Devices and Fields. 33(1) (2020) e2679.

[12] R.D. Muhammad, F. Faisal, Design of Optimal PID Controller For Three Phase Induction Motor Based on Ant Colony Optimization. Sinergi, 24(2) (2020) 125-132.

[13] G. Farahani, K. Rahmani, Speed control of a separately excited DC motor using new proposed fuzzy neural algorithm based on FOPID controller. Journal of Control, Automation and Electrical Systems. 30(5) (2019) 728-740.

[14] P. Dutta, S.K. Nayak, Grey Wolf Optimizer Based PID Controller for Speed Control of BLDC Motor. Journal of Electrical Engineering \& Technology. (2021) 1-7.

[15] C. Huang, F. Lei, X. Han, Z. Zhang, Determination of modeling parameters for a brushless DC motor that satisfies the power performance of an electric vehicle. Measurement and Control, 52(78) (2019) 765-774.

[16] J. Zhang, L. Guo, Theory and design of PID controller for nonlinear uncertain systems. IEEE Control Systems Letters. 3(3) (2019) 643-648.

[17] V.Y. Vorobyov, G.V. Sablina, Calculation and Optimization of Parameters of the Discrete PIDcontroller by the Ziegler-Nichols Method. Automatics \& Software Enginery. N1(27) (2019) 7.

[18] Y. Dhieb, M. Yaich, A. Guermazi, M. Ghariani, PID controller tuning using ant colony optimization for induction motor. Journal of Electrical Systems. 15(1) (2019) 133-141.

[19] R. Singh, B. Bhushan, Improved ant colony optimization for achieving self-balancing and position control for balancer systems. Journal of Ambient Intelligence and Humanized Computing. (2020) $1-18$.

[20] Y.T. Hsiao, C.L. Chuang, C.C. Chien, Ant colony optimization for designing of PID controllers. IEEE International Conference on Robotics and Automation (2004) 321-326. 